\title{
Modifikasi SHA-256 dengan Algoritma Hill Cipher untuk Pengamanan Fungsi Hash dari Upaya Decode Hash
}

\author{
${ }^{* \# 1}$ Zaimah Panjaitan, ${ }^{\# 1}$ Erika Fahmi Ginting, ${ }^{\# 2}$ Yusnidah \\ \#1Program Studi Sistem Informasi, STMIK Triguna Dharma \\ ${ }^{\# 2}$ Akademi Maritim Indonesia
}

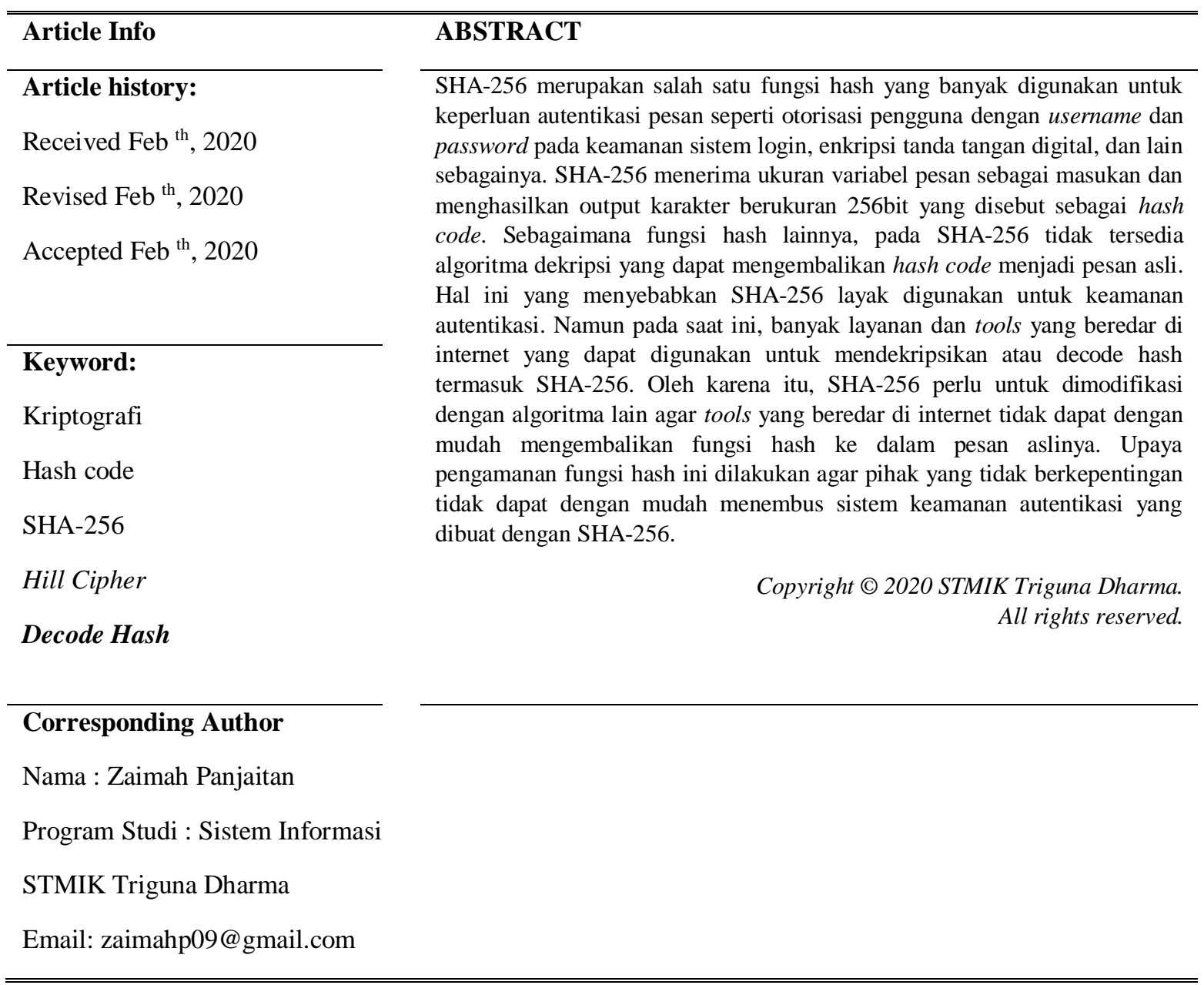

\section{PENDAHULUAN}


SHA-256 merupakan salah satu fungsi hash. Fungsi hash banyak digunakan pada enkripsi password akun pengguna website. Dengan fungsi hash ini, password yang dimasukkan pengguna saat login akan secara otomatis berubah menjadi pesan yang panjangnya tetap dan tidak diketahui maknanya bahkan oleh pemilik pesan dalam hal ini pemilik password, dan penyedia layanan keamanan dalam hal ini pemilik website yang membubuhkan keamanan pada situsnya. Karena pada dasarnya fungsi hash satu arah tidak dapat mengembalikan pesan pada bentuk aslinya. Hal inilah yang menjadi penyebab mengapa fungsi hash selalu digunakan dalam penyandian password.

SHA-256 mengubah pesan masukan ke dalam message digest (MD) sebesar 256 bit. Jika pesan masukan kurang atau lebih dari 264 bit, maka pesan tersebut harus dioperasikan oleh 512 bit dalam kelompok dan menjadi sebuah MD yang panjangnya tetap, yaitu 256 bit.

Dewasa ini, banyak tools dan layannan yang tersedia diinternet yang berfungsi untuk mendekripsi atau mengembalikan MD ke dalam pesan asli. Hal ini menyebabkan tingkat keamanan SHA-256 menjadi sangat rendah. Oleh karena itu dibutuhkan modifikasi pada SHA-256.

Pada penelitian ini, akan dilakukan modifikasi SHA-256 dengan algoritma Hill Cipher untuk menghasilkan MD berbeda yang jika didekripsi dengan cara decode hash, hasilnya masih berupa cipherteks. Dengan demikian, pihak yang tidak berkepentingan tidak dapat mengetahui secara langsung isi pesan yang di decode dengan tools decode hash tersebut.

\section{METODE PENELITIAN}

Sebelum melakukan penelitian, diperlukan suatu metodologi atau kaidah-kaidah yang harus dilakukan untuk menunjang keabsahan penelitian yang dilakukan. Hal ini dimaksudkan untuk memaksimalkan hasil penelitian nantinya. Metodologi penelitian ini akan memuat beberapa kerangka kerja penelitian yang akan dilakukan.

Langkah pertama yang dilakukan dalam penelitian ini adalah analisis kebutuhan. Masalah yang diidentifikasi pada penelitian ini adalah ancaman keamanan pada fungsi hash SHA-256 yang pada dasarnya tidak dapat didekripsi, namun karena beredar tools dan layaran di internet yang dapat mendekripsi atau decode hash, sehingga perlu dilakukan pengamanan pada SHA-256 dengan memodifikasinya dengan algoritma lain dalam hal ini algoritma Hill Cipher.

Kemudian selanjutnya langkah kedua yaitu dilakukan analisa pada modifikasi SHA-256 dengan algoritma Hill Cipher. Dalam hal ini akan dilakukan enkripsi pesan dengan SHA-256 untuk menghasilkan MD atau hash code sepanjang 256bit. Kemudian, MD yang sudah di dapatkan akan dienkripsi kembali dengan algoritma Hill Cipher yang bertujuan agar saat seseorang mendekripsi MD dengan tools decode hash, maka pesan yang dihasilkan berupa cipherteks yang tidak diketahui makna aslinya. Dengan demikian, keamanan MD dapat ditingkatkan.

Langkah terahir berupa pengujian. Untuk menguji hasil penelitian ini, dilakukan decode hash dengan tools yang tersedia di internet pada sebuah pesan yang dienkripsi dengan SHA-256. Kemudian dilakukan perbandingan dengan menguji decode hash yang dienkripsi dengan SHA-256 yang dimodifikasi dengan algoritma Hill Cipher. Dengan begitu dapat dibedakan hasil yang didapat dari kedua percobaan dan dibandingkan tingkat keamanannya.

\section{ANALISA DAN HASIL}

\subsection{SHA-256}

SHA-2 adalah sebuah kriptografi fungsi hash yang dirancang oleh National Security Agency (NSA) dan dipublikasikan oleh National Institute of Standart and Technology (NIST) sebagai sebuah Federal Information Processing Standart (FIPS) oleh U.S. Ada empat algoritma untuk keamanan fungsi hash yaitu

Jurnal SAINTIKOM Vol. 19, No.1, Februari 2020 : 53-61 
SHA-0, SHA-1, SHA-2, dan SHA-3. NIST memperbaharui SHA-2, dengan panjang output (256 atau 512- bit di atas 160-bit pada SHA-1) dan perbedaan-perbedaan pada SHA ini merupakan besar pesan yang ada pada proses komputasi[1].

SHA (Algoritma keamanan fungsi hash) merupakan algoritma enkripsi fungsi hash yang dapat digunakan untuk menghasilkan penggambaran konsolidasi dari sebuah data teks yang disebut sebuah proses pesan. SHA-256 dan SHA-512 adalah fungsi hash dengan kapasitas terbaru dengan panjang 32-bit dan 64-bit kata secara terpisah. Kedua fungsi hash ini dalam proses matematisnya menggunakan penjumlahan karakter yang berbeda dan ditambah dengan konstanta substansi. Meski demikian, struktur keduanya pada dasarnya tidak jauh berbeda, perbedaannya hanya terletak pada jumlah putaran saja[2].

Arsitektur sederhana dari algoritma SHA-256 ditunjukkan oleh gambar berikut:

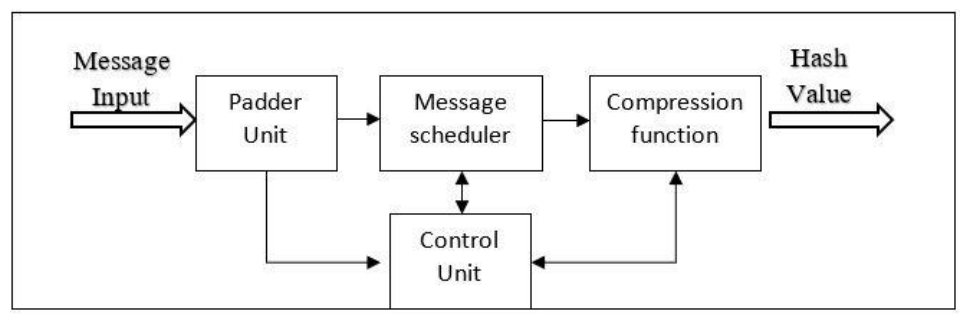

Gambar 1. Arsitektur Sederhana SHA-256.

Berikut merupakan jalur komputasi SHA-2:

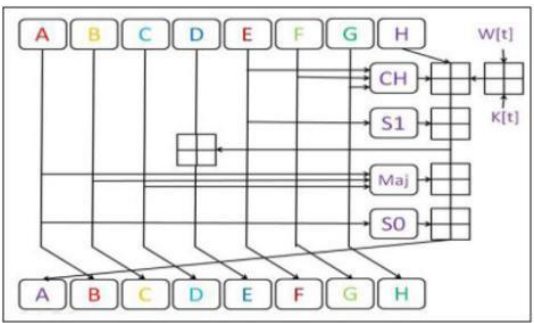

Gambar 2. Jalur Komputasi SHA-256

Adapun proses atau tahapan pada algoritma SHA-256 adalah sebagai berikut :

1. Message Padding

Pada tahap pertama ini, pesan berupa binary disisipkan dengan angka 1 dan ditambahkan bit-bit pengganjal, yakni angka 0 hingga panjang pesan kongruen dengan 448 modulo 512. Panjang pesan asli ditambah sebagai angka biner 64 bit. Maka panjang pesan sekarang menjadi kelipatan 512 bit.

2. Parsing

Pada proses ini, pesan yang telah dipadding kemudian dibagi menjadi $\mathrm{N}$ buah blok 512 bit : $M^{(1)}, M^{(2)}, \ldots M^{(n)}$

\section{Message Expansion}

Masing-masing blok 512 bit tadi dipecah menjadi 16 word 32 bit : $M_{0}^{(i)}, M_{1}^{(i)}, \ldots M_{15}^{(i)}$

Kemudian akan diperluas menjadi 64 word yang diberli label W0, W1,..W63. 


\section{Message Compression}

Masing-masing dari 64 word yang diberi label W0, W1,..W64 tadi diproses denga algoritma fungsi hash SHA-256.

Dalam proses tersebut, inti utama dari algoritma SHA-256 adalah membuat 8 variabel yang diberikan nilai awal L0-L7. Nilai awal tersebut adalah sebagai berikut :

Tabel 1. Nilai Awal Variabel SHA-256

\begin{tabular}{|r|r|r|r|r|r|}
\hline L0 & $\mathrm{a}$ & 6A09E667 & L4 & $\mathrm{e}$ & 510E527F \\
\hline L1 & $\mathrm{b}$ & BB67AE85 & L5 & $\mathrm{f}$ & 9B05688C \\
\hline L2 & $\mathrm{c}$ & 3C6EF372 & L6 & $\mathrm{g}$ & IF83D9AB \\
\hline L3 & $\mathrm{d}$ & A54FF53A & L7 & $\mathrm{h}$ & 5BE0CD19 \\
\hline
\end{tabular}

5. Kemudian dilakukan perhitungan sebanyak 64 kali pitaran untuk setiap blok. Delapan variabel yang diberikan pada nilai awal berupa L0 sampai dengan L7 asumsikan menjadi nilai A,B,C,D,E,F,G, dan H nilainya terus berganti selama perputaran dengan rumus sebagai berikut :

$T 1=h+s 1+C H+K[t]+W[t]$

$T 2=s 0+M A J$

$h=g$

$g=f$

$f=e$

$e=d+T 1$

$d=c$

$c=b$

$b=a$

$a=T 1+T 2$

Keterangan :

$s 0=(a \gg>2) \oplus(a \gg>13) \oplus(a \gg>22)$

$s 1=(e \gg>6) \oplus(e \gg>11) \oplus(e \gg>25)$

$C H=(e \& f) \oplus((\neg e) \& g))$

$M A J=(a \& b) \oplus(a \& c) \oplus(b \& c)$

Nilai ahir hash adalah sebagai berikut :

$$
L 0=L 0+a
$$




$$
\begin{aligned}
& L 1=L 1+b \\
& L 2=L 2+c \\
& L 3=L 3+d \\
& L 4=L 4+e \\
& L 5=L 5+f \\
& L 6=L 6+g \\
& L 7=L 7+h
\end{aligned}
$$

Maka, MD yang didapatkan adalah hasil ahir penjumlahan yang disusun secara memanjang [3].

\subsection{Hill Cipher}

Hill Cipher adalah teknik kriptografi cipher block dengan kunci simetris yang dikembangkan oleh matematikawan Lester pada tahun 1929[4]. Algoritma Hill Cipher menggunakan matriks berukuran m x m sebagai kunci untuk proses enkripsi dan dekripsi [5]. Pada algoritma Hill Cipher pengirim dan penerima harus berbagi dan menggunakan kunci berupa matriks yang sama untuk proses enkripsi dan dekripsinya [6]. Teknik kriptografi ini diciptakan dengan maksud untuk dapat menciptakan Cipher (kode) yang tidak dapat dipecahkan menggunakan teknik analisis frekuensi [7].

Algoritma Hill Cipher adalah salah satu algoritma klasik, namun dibandingkan dengan algoritma kriptografi klasik lainnya Hill Cipher dianggap cukup kuat karena menggunakan matriks sebagai kuncinya. Hal ini menyebabkan cipher teks yang dihasilkan oleh algoritma ini lebih sulit untuk dipecahkan oleh kriptanalis.

Hill Cipher termasuk kepada algoritma kriptografi klasik yang sangat sulit dipecahkan oleh kriptanalis apabila dilakukan hanya dengan mengetahui berkas ciphertext saja. Karena Hill Cipher tidak mengganti setiap abjad yang sama pada plaintext dengan abjad lainnya yang sama pada ciphertext karena menggunakan perkalian matriks pada dasar enkripsi dan dekripsinya [8]

Proses enkripsi pada Hill Cipher dilakukan dengan mengalikan setiap blok plainteks dengan kunci yang telah disediakan terlebih dahulu. Kunci yang dibuat adalah berupa matriks yang invertible atau memiliki invers. Berikut adalah flowchart enkripsi dari Hill Cipher :

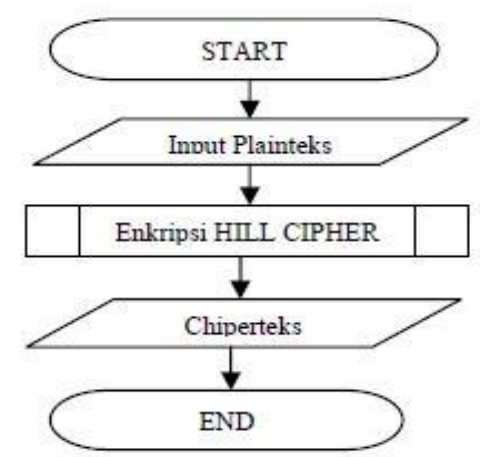

Gambar 3. Flowchart Enkripsi Hill Cipher 
Secara matematis, proses enkripsi pada Hill Cipher adalah [9]:

$\mathrm{C}=\mathrm{K} \cdot \mathrm{P}$

Dimana :

$\mathrm{C}=$ Cipherteks

$\mathrm{K}=$ Kunci

$\mathrm{P}=$ Plainteks

Adapun pembentukan kunci Hill Cipher adalah dengan membentuk matriks m x m yang invertible yaitu sesuai dengan persamaan :

$\mathrm{K} \cdot \mathrm{K}^{-1}=\mathrm{I}$

Dimana :

$\mathrm{K}=$ Matriks kunci

$\mathrm{K}^{-1}=$ Invers matriks kunci

I = Matriks identitas

Sebelum dilakukan proses enkripsi pada plainteks, terlebih dahulu plainteks diubah ke dalam angka 0-25 dengan sekema sebagai berikut :

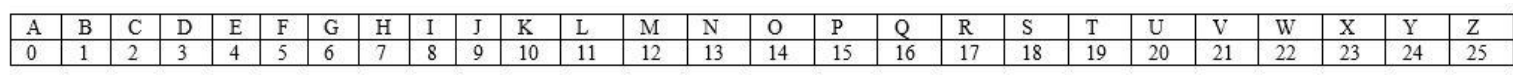

Gambar 4. Skema Angka Pada Hill Cipher

Kemudian proses dekripsi pada Hill Cipher adalah kebalikan dari proses enkripsi, secara matematis :

$\mathrm{P}=\mathrm{K}^{-1} \cdot \mathrm{C}$

Dimana :

$\mathrm{P}=$ Plainteks

$\mathrm{K}^{-1}=$ Invers matriks kunci, untuk menentukannya berlaku rumus 1/det $\mathrm{K}$ mod 26.

$\mathrm{C}=$ Cipherteks

\subsection{Modifikasi SHA-256 dengan Algoritma Hill Cipher}

Pada kasus ini plainteks dienkripsi dengan SHA-256 untuk menghasilkan string hash code, kemudian untuk memperkuat hash tersebut agar tidak dapat didekripsi oleh layanan tools decode hash, maka akan dilakukan enkrispsi hash dengan algoritma Hill Cipher.

Pesan yang dienkripsi dalam hal ini berupa angka misalnya : 347 (angka ini hanya contoh untuk mempermudah proses perhitungan secara manual). Adapun tahapannya sebagai berikut :

1. Pesan diubah ke bentuk biner :

$3=00000011$

Jurnal SAINTIKOM Vol. 19, No.1, Februari 2020 : 53-61 
$4=00000100$

$7=00000111$

Maka pesan, $\mathrm{M}=000000110000010000000111$.

Panjang pesan, $1=24$ bit

\section{Message Padding}

Padding pesan dilakukan dengan cara menambahkan bit 1 dan sisanya adalah bit 0 hingga pesan sepanjang 512 bit. Untuk mencari jumlah nol yang ditambahkan (k) digunakan rumus berikut:

$l+1+k \equiv 448 \bmod 512$

$24+1+k \equiv 448 \bmod 512$

$k \equiv 448-25 \bmod 512$

$k \equiv 423$

Karena k = 423 maka banyaknya bit 0 yang akan ditambahkan adalah sebanyak 423 bit. Setelah itu ditambahkan jumlah panjang pesan pada akhir pesan yang dipadding sebanyak 8 bit dengan nilai $1=24=$ 00011000

Tabel 2. Hasil Padding Pesan

\begin{tabular}{|l|l|l|l|l|l|l|l|}
\hline 00000011 & 00000100 & 00000111 & 10000000 & 00000000 & 00000000 & 00000000 & 00000000 \\
\hline 00000000 & 00000000 & 00000000 & 00000000 & 00000000 & 00000000 & 00000000 & 00000000 \\
\hline 00000000 & 00000000 & 00000000 & 00000000 & 00000000 & 00000000 & 00000000 & 00000000 \\
\hline 00000000 & 00000000 & 00000000 & 00000000 & 00000000 & 00000000 & 00000000 & 00000000 \\
\hline 00000000 & 00000000 & 00000000 & 00000000 & 00000000 & 00000000 & 00000000 & 00000000 \\
\hline 00000000 & 00000000 & 00000000 & 00000000 & 00000000 & 00000000 & 00000000 & 00000000 \\
\hline 00000000 & 00000000 & 00000000 & 00000000 & 00000000 & 00000000 & 00000000 & 00000000 \\
\hline 00000000 & 00000000 & 00000000 & 00000000 & 00000000 & 00000000 & 00000000 & 00011000 \\
\hline
\end{tabular}

\section{Parsing}

Pesan yang telah dipadding akan menghasilkan blok pesan 512 bit $\mathrm{M}(0), \mathrm{M}(1), \ldots \mathrm{M}(\mathrm{n}-1)$. Namun, dalam contah kasus ini karena panjang pesan yang dipadding tidak melebihi 512 bit, maka hanya menghasilkan satu blok 512 bit yaitu $\mathrm{M}(0)$.

Tahapan selanjutnya adalah membagi setiap blok 512 bit menjadi 16 buah word 32 bit sebagai berikut :

Tabel 3. Hasil Parsing Pesan

\begin{tabular}{|l|l|l|l|l|l|l|l|l|}
\hline $\mathrm{M}_{0}^{(0)}$ & 0000 & 0011 & 0000 & 0100 & 0000 & 0111 & 1000 & 0000 \\
\hline $\mathrm{M}_{0}^{(1)}$ & 0000 & 0000 & 0000 & 0000 & 0000 & 0000 & 0000 & 0000 \\
\hline $\mathrm{M}_{0}^{(2)}$ & 0000 & 0000 & 0000 & 0000 & 0000 & 0000 & 0000 & 0000 \\
\hline $\mathrm{M}_{0}^{(3)}$ & 0000 & 0000 & 0000 & 0000 & 0000 & 0000 & 0000 & 0000 \\
\hline $\mathrm{M}_{0}^{(4)}$ & 0000 & 0000 & 0000 & 0000 & 0000 & 0000 & 0000 & 0000 \\
\hline $\mathrm{M}_{0}^{(5)}$ & 0000 & 0000 & 0000 & 0000 & 0000 & 0000 & 0000 & 0000 \\
\hline $\mathrm{M}_{0}^{(6)}$ & 0000 & 0000 & 0000 & 0000 & 0000 & 0000 & 0000 & 0000 \\
\hline
\end{tabular}




\section{Message Schadule}

\begin{tabular}{|l|l|l|l|l|l|l|l|l|}
\hline $\mathrm{M}_{0}{ }^{(7)}$ & 0000 & 0000 & 0000 & 0000 & 0000 & 0000 & 0000 & 0000 \\
\hline $\mathrm{M}_{0}{ }^{(8)}$ & 0000 & 0000 & 0000 & 0000 & 0000 & 0000 & 0000 & 0000 \\
\hline $\mathrm{M}_{0}^{(9)}$ & 0000 & 0000 & 0000 & 0000 & 0000 & 0000 & 0000 & 0000 \\
\hline $\mathrm{M}_{0}{ }^{(10)}$ & 0000 & 0000 & 0000 & 0000 & 0000 & 0000 & 0000 & 0000 \\
\hline $\mathrm{M}_{0}^{(11)}$ & 0000 & 0000 & 0000 & 0000 & 0000 & 0000 & 0000 & 0000 \\
\hline $\mathrm{M}_{0}^{(12)}$ & 0000 & 0000 & 0000 & 0000 & 0000 & 0000 & 0000 & 0000 \\
\hline $\mathrm{M}_{0}^{(13)}$ & 0000 & 0000 & 0000 & 0000 & 0000 & 0000 & 0000 & 0000 \\
\hline $\mathrm{M}_{0}^{(14)}$ & 0000 & 0000 & 0000 & 0000 & 0000 & 0000 & 0000 & 0000 \\
\hline $\mathrm{M}_{0}^{(15)}$ & 0000 & 0000 & 0000 & 0000 & 0000 & 0000 & 0001 & 1000 \\
\hline
\end{tabular}

Selanjutnya, masing-masing 16 word di atas diperluas menjadi 64 buah 32 bit word sebagai berikut:

Tabel 4. Hasil Message Schadule

\begin{tabular}{|c|l|l|l|l|l|l|l|}
\hline $\mathrm{W}_{0}$ & 03040780 & $\mathrm{~W}_{16}$ & 00000000 & $\mathrm{~W}_{32}$ & 00000000 & $\mathrm{~W}_{48}$ & 00000000 \\
\hline $\mathrm{W}_{1}$ & 00000000 & $\mathrm{~W}_{17}$ & 00000000 & $\mathrm{~W}_{33}$ & 00000000 & $\mathrm{~W}_{49}$ & 00000000 \\
\hline $\mathrm{W}_{2}$ & 00000000 & $\mathrm{~W}_{18}$ & 00000000 & $\mathrm{~W}_{34}$ & 00000000 & $\mathrm{~W}_{50}$ & 00000000 \\
\hline $\mathrm{W}_{3}$ & 00000000 & $\mathrm{~W}_{19}$ & 00000000 & $\mathrm{~W}_{35}$ & 00000000 & $\mathrm{~W}_{51}$ & 00000000 \\
\hline $\mathrm{W}_{4}$ & 00000000 & $\mathrm{~W}_{20}$ & 00000000 & $\mathrm{~W}_{36}$ & 00000000 & $\mathrm{~W}_{52}$ & 00000000 \\
\hline $\mathrm{W}_{5}$ & 00000000 & $\mathrm{~W}_{21}$ & 00000000 & $\mathrm{~W}_{37}$ & 00000000 & $\mathrm{~W}_{53}$ & 00000000 \\
\hline $\mathrm{W}_{6}$ & 00000000 & $\mathrm{~W}_{22}$ & 00000000 & $\mathrm{~W}_{38}$ & 00000000 & $\mathrm{~W}_{54}$ & 00000000 \\
\hline $\mathrm{W}_{7}$ & 00000000 & $\mathrm{~W}_{23}$ & 00000000 & $\mathrm{~W}_{39}$ & 00000000 & $\mathrm{~W}_{55}$ & 00000000 \\
\hline $\mathrm{W}_{8}$ & 00000000 & $\mathrm{~W}_{24}$ & 00000000 & $\mathrm{~W}_{40}$ & 00000000 & $\mathrm{~W}_{56}$ & 00000000 \\
\hline $\mathrm{W}_{9}$ & 00000000 & $\mathrm{~W}_{25}$ & 00000000 & $\mathrm{~W}_{41}$ & 00000000 & $\mathrm{~W}_{57}$ & 00000000 \\
\hline $\mathrm{W}_{10}$ & 00000000 & $\mathrm{~W}_{26}$ & 00000000 & $\mathrm{~W}_{42}$ & 00000000 & $\mathrm{~W}_{58}$ & 00000000 \\
\hline $\mathrm{W}_{11}$ & 00000000 & $\mathrm{~W}_{27}$ & 00000000 & $\mathrm{~W}_{43}$ & 00000000 & $\mathrm{~W}_{59}$ & 00000000 \\
\hline $\mathrm{W}_{12}$ & 00000000 & $\mathrm{~W}_{28}$ & 00000000 & $\mathrm{~W}_{44}$ & 00000000 & $\mathrm{~W}_{60}$ & 00000000 \\
\hline $\mathrm{W}_{13}$ & 00000000 & $\mathrm{~W}_{29}$ & 00000000 & $\mathrm{~W}_{45}$ & 00000000 & $\mathrm{~W}_{61}$ & 00000000 \\
\hline $\mathrm{W}_{14}$ & 00000000 & $\mathrm{~W}_{30}$ & 00000000 & $\mathrm{~W}_{46}$ & 00000000 & $\mathrm{~W}_{62}$ & 00000000 \\
\hline $\mathrm{W}_{15}$ & 00000018 & $\mathrm{~W}_{31}$ & 00000000 & $\mathrm{~W}_{47}$ & 00000000 & $\mathrm{~W}_{63}$ & 00000000 \\
\hline
\end{tabular}

5. Inisialisasi Variabel dan Konstanta

Variabel awal pada fungsi hash SHA-256 adalah sebagai berikut :

$$
\begin{aligned}
& \mathrm{a}=\mathrm{H} 0(0)=6 \mathrm{~A} 09 \mathrm{E} 667 \\
& \mathrm{~b}=\mathrm{H} 0(1)=\mathrm{BB} 67 \mathrm{AE} 85 \\
& \mathrm{c}=\mathrm{H} 0(2)=3 \mathrm{C} 6 \mathrm{EF} 372 \\
& \mathrm{~d}=\mathrm{H} 0(3)=\mathrm{A} 54 \mathrm{FF} 53 \mathrm{~A}
\end{aligned}
$$




$$
\begin{aligned}
& \mathrm{e}=\mathrm{H} 0(4)=510 \mathrm{E} 527 \mathrm{~F} \\
& \mathrm{f}=\mathrm{H} 0(5)=9 \mathrm{~B} 05688 \mathrm{C} \\
& \mathrm{g}=\mathrm{H} 0(6)=1 \mathrm{~F} 83 \mathrm{D} 9 \mathrm{AB} \\
& \mathrm{h}=\mathrm{H} 0(7)=5 \mathrm{BE} 0 \mathrm{CD} 19
\end{aligned}
$$

\begin{tabular}{|c|c|c|c|c|c|c|c|}
\hline 428A2F98 & 71374491 & B5COFBCF & E9B5DBA5 & $3956 C 25 B$ & 59F111F1 & 923F82A4 & AB1C5ED5 \\
\hline D807AA98 & 12835B01 & 243185BE & $550 C 7 D C 3$ & 72BE5D74 & 80DEB1FE & 9BDC06A7 & C19BF174 \\
\hline E49B69C1 & EFBE4786 & OFC19DC6 & 240CA1CC & 2DE92C6F & 4A7484AA & 5CB0A9DC & 76F988DA \\
\hline 983E5152 & A831C66D & B00327C8 & BF597FC7 & C6E00BF3 & D5A79147 & 06CA6351 & 14292967 \\
\hline 27B70A85 & 2E1B2138 & 4D2C6DFC & 53380D13 & 650A7354 & 766A0ABB & $81 \mathrm{C} 2 \mathrm{C} 92 \mathrm{E}$ & $92722 \mathrm{C} 85$ \\
\hline A2BFE8A1 & A81A664B & C24B8B70 & C76C51A3 & D192E819 & D6990624 & F40E3585 & 106AA070 \\
\hline 19A4C116 & 1E376C08 & $2748774 C$ & 34В0ВCB5 & 391 COCB3 & 4ED8AA4A & 5B9CCA4F & 682E6FF3 \\
\hline $748 \mathrm{~F} 82 \mathrm{EE}$ & 78A5636F & $84 C 87814$ & $8 C C 70208$ & 90BEFFFA & A4506CEB & BEF9A3F7 & C67178F2 \\
\hline
\end{tabular}

Nilai konstanta pada fungsi hash SHA-256 (K0\{256\}, K1 $\{256\}, \ldots . . . \mathrm{K} 63\{256\})$ adalah sebagai berikut :

Tabel

Nilai

Konstanta SHA-256

\section{Hash Computation}

Dalam proses ini dilakukan perhitungan nilai a sampai nilai h sebanyak 64 kali putaran. Adapun bentuk perhitungannya adalah sebagai berikut : 


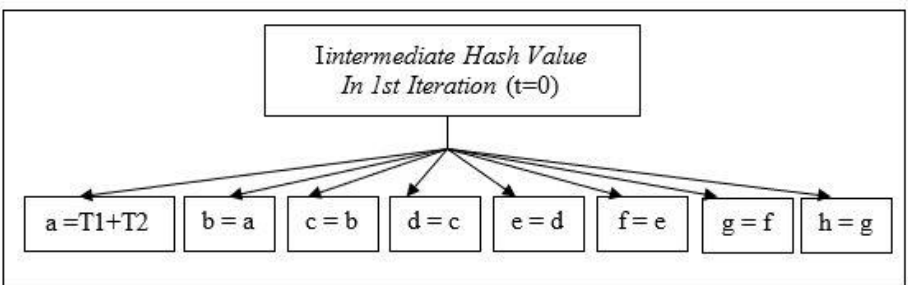

Gambar 5. Intermediate Hash Value In $1^{\text {st }}$ Iteration

Rumus untuk menghasilkan nilai T1 adalah :

$T 1=h+S 1(e)+\operatorname{ch}(e, f, g)+k t+w t$

Di mana,

$\mathrm{h}=$ Nilai $\mathrm{h}$ pada iterasi sebelumnya

$\mathrm{S} 1(\mathrm{e}) \quad=(e \gg>6) \oplus(e \gg>11) \oplus(e \gg>25)$

Ch $(\mathrm{e}, \mathrm{f}, \mathrm{g}) \quad=(e \& f) \oplus((\neg e) \& g))$

Kt $=$ Nilai konstanta

$\mathrm{Wt}=$ Nilai $\mathrm{W}$ pada Message Schadule

Maka nilai T1 adalah sebagai berikut :

$h=5 B E 0 C D 19$

$\operatorname{Si}(e)=(510 E 527 F \gg>6) \oplus(510 E 527 F \gg>11) \oplus(510 E 527 F \gg>11)$

$\operatorname{Si}(e)=3587272 B$

$\operatorname{ch}(e, f, g)=(510 E 527 F \& 9 B 05688 C \oplus((\neg 510 E 527 F) \& 1 F 83 D 9 A B))$

$\operatorname{ch}(e, f, g)=1 F 85 C 98 C$

$$
T 1=5 B E 0 C D 19+3587272 B+1 F 85 C 98 C+428 A 2 F 98+03040780
$$

$T 1=F 67 B F 4 E 8$

Rumus untuk menghasilkan nilai T2 adalah sebagai berikut :

$T 2=S 0(a)+\operatorname{Maj}(a, b, c)$

Di mana,

$\mathrm{S} 0(\mathrm{a}) \quad=(a \gg>2) \oplus(a \gg>13) \oplus(a \gg>22)$

$\operatorname{Maj}(\mathrm{a}, \mathrm{b}, \mathrm{c}) \quad=(a \& b) \oplus(a \& c) \oplus(b \& c)$

Maka nilai T2 adalah sebagai berikut :

$S 0(a)=(6 A 09 E 667 \gg>2) \oplus(6 A 09 E 667 \gg>13) \oplus(6 A 09 E 667 \gg>22)$

$S 0(a)=C E 20 B 47 E$

$\operatorname{Maj}(a, b, c)=(6 A 09 E 667 \& B B 67 A E 85) \oplus(6 A 09 E 667 \& 3 C 6 E F 372) \oplus(B B 67 A E 85 \& 3 C 6 E F 372)$

$\operatorname{Maj}(a, b, c)=3 A 6 F E 667$

Jurnal SAINTIKOM Vol. 19, No.1, Februari 2020 : 53-61 
$T 2=C E 20 B 47 E+3 A 6 F E 667$

$T 2=08909 A E 5$

Karena nilai T1 dan T2 telah didapatkan, maka nilai a adalah sebagai berikut :

$a=T 1+T 2$

$a=F 67 B F 4 E 8+08909 A E 5$

$a=F F 0 C 8 F C D$

Maka putaran pertama $(\mathrm{t}=0)$ hash code dari pesan “347” adalah sebagai berikut:

Tabel 6. Nilai putaran pertama

\begin{tabular}{|c|c|c|c|c|c|c|c|c|}
\hline & $\mathrm{a}$ & $\mathrm{b}$ & $\mathrm{c}$ & $\mathrm{d}$ & $\mathrm{e}$ & $f$ & $\mathrm{~g}$ & $\mathrm{~h}$ \\
\hline init & 6a09e667 & bb67ae85 & $3 \operatorname{cbef} 372$ & a54ff53a & $510 \mathrm{e} 527 \mathrm{f}$ & $9 \mathrm{~b} 05688 \mathrm{c}$ & 1f83d9ab & $5 b e 0 c 019$ \\
\hline$t=0$ & ff0c8fcd & 6a09e667 & bb67ae85 & 3cbef372 & a54ff53a & $510 \mathrm{e} 527 \mathrm{f}$ & $9 \mathrm{~b} 05688 \mathrm{c}$ & $1 \mathrm{f} 83 \mathrm{~d} 9 \mathrm{ab}$ \\
\hline
\end{tabular}

Selanjutnya dilakukan lagi pencarian nilai a untuk putaran kedua dan seterusnya hingga putaran $64(\mathrm{t}=63)$.

\section{Compute intermediate hash value + initial hash value}

Setelah didapat ke 64 putaran dari hash computation, kemudian pada tahap ini dilakukan proses penjumlahan hasil putaran yang ke-64 dengan initial hash value. Maka hasil yang didapatkan adalah sebagai berikut:

$$
\begin{aligned}
& \mathrm{H} 0(0)=\mathrm{b} 87 \mathrm{fcbba}+6 \mathrm{a} 09 \mathrm{e} 667=2289 \mathrm{~b} 221 \\
& \mathrm{H} 0(1)=\mathrm{f} 82 \mathrm{e} 573 \mathrm{e}+\mathrm{bb} 67 \mathrm{ae} 85=\mathrm{b} 39605 \mathrm{c} 3 \\
& \mathrm{H} 0(2)=0 \mathrm{cdf} 7 \mathrm{f} 1 \mathrm{e}+3 \mathrm{c} 6 \mathrm{ef} 372=494 \mathrm{e} 7290 \\
& \mathrm{HO}(3)=\mathrm{e} 01223 \mathrm{af}+\mathrm{a} 54 \mathrm{ff} 53 \mathrm{a}=856218 \mathrm{e} 9 \\
& \mathrm{HO}(4)=\mathrm{e} 0 \mathrm{~b} 1 \mathrm{~b} 876+510 \mathrm{e} 527 \mathrm{f}=31 \mathrm{c} 00 \mathrm{af} 5 \\
& \mathrm{HO}(5)=\mathrm{bbca} 117 \mathrm{~b}+9 \mathrm{~b} 05688 \mathrm{c}=56 \mathrm{cf} 7 \mathrm{a} 07 \\
& \mathrm{HO}(6)=62 \mathrm{ed} 2 \mathrm{e} 6 \mathrm{e}+1 \mathrm{f} 83 \mathrm{~d} 9 \mathrm{ab}=82710819 \\
& \mathrm{HO}(7)=\mathrm{df} 4697 \mathrm{f} 8+5 \mathrm{be} 0 \mathrm{~cd} 19=3 \mathrm{~b} 276511
\end{aligned}
$$

8. penggaabungan $\mathrm{H} 0-\mathrm{H} 7$

H0|| H1|| H2|| H3|| H4|| H5|| H6|| H7

2289b221||b39605c3||494e7290||856218e9||31c00af5||56cf7a07||82710819||3b276511

\section{Nilai hash}

Maka dengan seluruh proses yang dilalui didapatlah nilai hash sebagai berikut: 
Hash code yang telah didapatkan di atas kemudian dienkripsi dengan algoritma Hill Cipher :

1. Menentukan kunci.

Dalam hal ini karena hash code terdiri dari 64 karakter. Matriks kunci kita bentuk berupa matriks 2 x 2 sehingga perkalian matriks dilakukan dengan setiap 2 blok pesan. Adapun matriks kunci adalah :

$K=\left[\begin{array}{ll}5 & 3 \\ 3 & 2\end{array}\right] \times \quad K^{-1}=\left[\begin{array}{ll}5 & 3 \\ 3 & 2\end{array}\right]=\left[\begin{array}{cc}79 & 130 \\ 52 & 79\end{array}\right] \bmod 26=\left[\begin{array}{ll}1 & 0 \\ 0 & 1\end{array}\right]$

\section{Mengkonversi plainteks.}

Karena plainteks terdiri dari angka dan huruf, maka konversinya sebagai berikut :

\begin{tabular}{|l|l|l|l|l|l|l|l|l|l|l|l|l|l|l|l|l|l|}
\hline A & B & C & D & E & F & G & H & I & J & K & L & M & N & O & P & Q & R \\
\hline 0 & 1 & 2 & 3 & 4 & 5 & 6 & 7 & 8 & 9 & 10 & 11 & 12 & 13 & 14 & 15 & 16 & 17 \\
\hline
\end{tabular}

\begin{tabular}{|l|l|l|l|l|l|l|l|l|l|l|l|l|l|l|l|l|l|}
\hline $\mathrm{S}$ & $\mathrm{T}$ & $\mathrm{U}$ & $\mathrm{V}$ & $\mathrm{W}$ & $\mathrm{X}$ & $\mathrm{Y}$ & $\mathrm{Z}$ & 0 & 1 & 2 & 3 & 4 & 5 & 6 & 7 & 8 & 9 \\
\hline 18 & 19 & 20 & 21 & 22 & 23 & 24 & 25 & 26 & 27 & 28 & 29 & 30 & 31 & 32 & 33 & 34 & 35 \\
\hline
\end{tabular}

Jika plainteks berupa hash di atas dikonversi, maka kasilnya sebagai berikut :

Tabel 7. Nilai konversi pesan

\begin{tabular}{|c|c|c|c|c|c|c|c|}
\hline $\begin{array}{l}2= \\
28\end{array}$ & $\mathrm{~b}=1$ & $\begin{array}{l}4= \\
30\end{array}$ & $\begin{array}{l}8= \\
34\end{array}$ & $\begin{array}{l}3= \\
29\end{array}$ & $\begin{array}{ll}5 & = \\
31 & \end{array}$ & $8=34$ & $\begin{array}{l}3= \\
29\end{array}$ \\
\hline $\begin{array}{l}2= \\
28\end{array}$ & $\begin{array}{l}3= \\
29\end{array}$ & $\begin{array}{l}9= \\
35\end{array}$ & $\begin{array}{l}5= \\
31\end{array}$ & $\begin{array}{l}1= \\
27\end{array}$ & $\begin{array}{l}6= \\
32=\end{array}$ & $2=28$ & $\mathrm{~b}=1$ \\
\hline $\begin{array}{l}8= \\
34\end{array}$ & $\begin{array}{l}9= \\
35\end{array}$ & $\begin{array}{l}4= \\
30\end{array}$ & $\begin{array}{l}6= \\
32=\end{array}$ & $c=2$ & $c=2$ & $7=33$ & $\begin{array}{ll}2 & = \\
28 & \end{array}$ \\
\hline $\begin{array}{l}9= \\
35\end{array}$ & $\begin{array}{l}6= \\
32\end{array}$ & $\mathrm{e}=4$ & $\begin{array}{ll}2 & = \\
28 & \end{array}$ & $\begin{array}{l}0= \\
26\end{array}$ & $f=5$ & $1=27$ & $\begin{array}{l}7= \\
33\end{array}$ \\
\hline $\mathrm{b}=1$ & $\begin{array}{l}0= \\
26\end{array}=$ & $\begin{array}{l}7 \\
33\end{array}=$ & $\begin{array}{l}1= \\
27\end{array}$ & $\begin{array}{l}0= \\
26\end{array}$ & $\begin{array}{l}7= \\
33\end{array}=$ & $0=26$ & $\begin{array}{l}6= \\
32=\end{array}$ \\
\hline $\begin{array}{l}2= \\
28\end{array}$ & $\begin{array}{l}5= \\
31\end{array}$ & $\begin{array}{l}2= \\
28\end{array}=$ & $\begin{array}{l}8= \\
34\end{array}$ & $a=0$ & $a=0$ & $8=34$ & $\begin{array}{l}5= \\
31\end{array}=$ \\
\hline $\begin{array}{l}2= \\
28\end{array}=$ & $\mathrm{c}=2$ & $\begin{array}{l}9= \\
35\end{array}=$ & $\mathrm{e}=4$ & $f=5$ & $\begin{array}{l}0= \\
26\end{array}=$ & $1=27$ & $\begin{array}{l}1= \\
27\end{array}$ \\
\hline $\begin{array}{l}1= \\
27\end{array}$ & $\begin{array}{l}3= \\
29\end{array}$ & $\begin{array}{l}0= \\
26\end{array}$ & $\begin{array}{l}9= \\
35\end{array}$ & $\begin{array}{l}5= \\
31\end{array}$ & $\begin{array}{l}7= \\
33\end{array}=$ & $=35$ & $\begin{array}{l}1= \\
27\end{array}$ \\
\hline
\end{tabular}

3. Mengalikan matriks kunci dengan blok plainteks, dan hasilnya di mod 26 :

Blok 1 :

Jurnal SAINTIKOM Vol. 19, No.1, Februari 2020 : 53-61 
$\left[\begin{array}{ll}5 & 3 \\ 3 & 2\end{array}\right] \times\left[\begin{array}{l}28 \\ 28\end{array}\right]=\left[\begin{array}{l}5 * 28+3 * 28 \\ 3 * 28+2 * 28\end{array}\right]=\left[\begin{array}{l}224 \bmod 26=16 \\ 140 \bmod 26=10\end{array}\right]$

Hasilnya, karakter pertama $16=\mathrm{q}$ dan karakter kedua $10=\mathrm{k}$.

Kemudian lakukan perhitungan pada seluruh hash code di atas sehingga mendapatkan hasil berupa hash code baru yaitu : qkpqihniojlnpktmvegupztbdikwdtveslkgaaozrbzqjvvoucmxyqgvslfutcif

\subsection{Pengujian}

Pada kasus ini akan dilihat bagaimana tools yang tersedia di internet dapat mendekripsi hash code yang tidak dimodifikasi dengan algoritma lain.

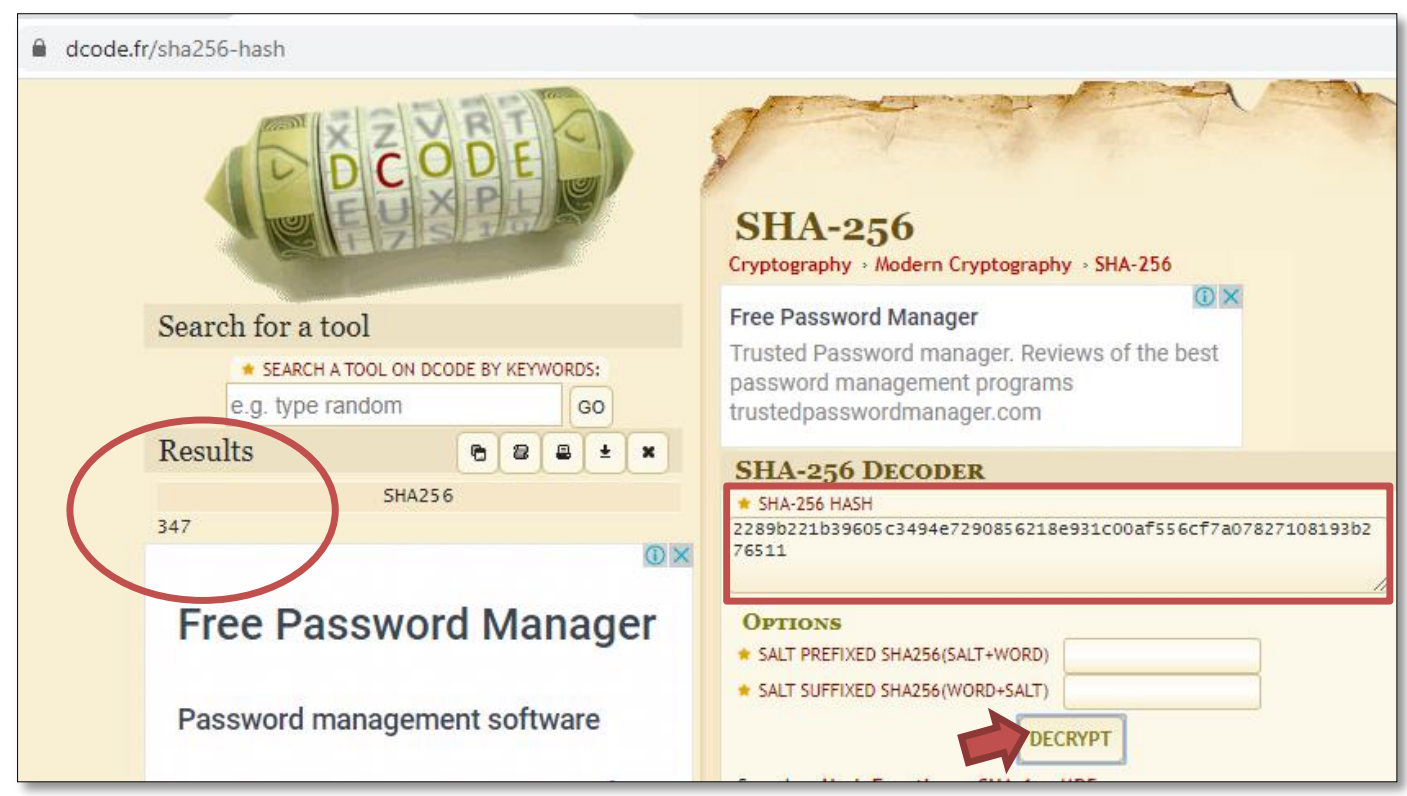

Gambar 6. Hasil Decode SHA-256

Ketika dimasukkan kode hash pada kolom yang disediakan, kemudian klik Decrypt maka hasilnya akan terlihat plainteks.

Jika dimasukkan hash code yang telah dimodifikasi dengan Hill Cipher, maka hasilnya akan tampak sebagai berikut : 


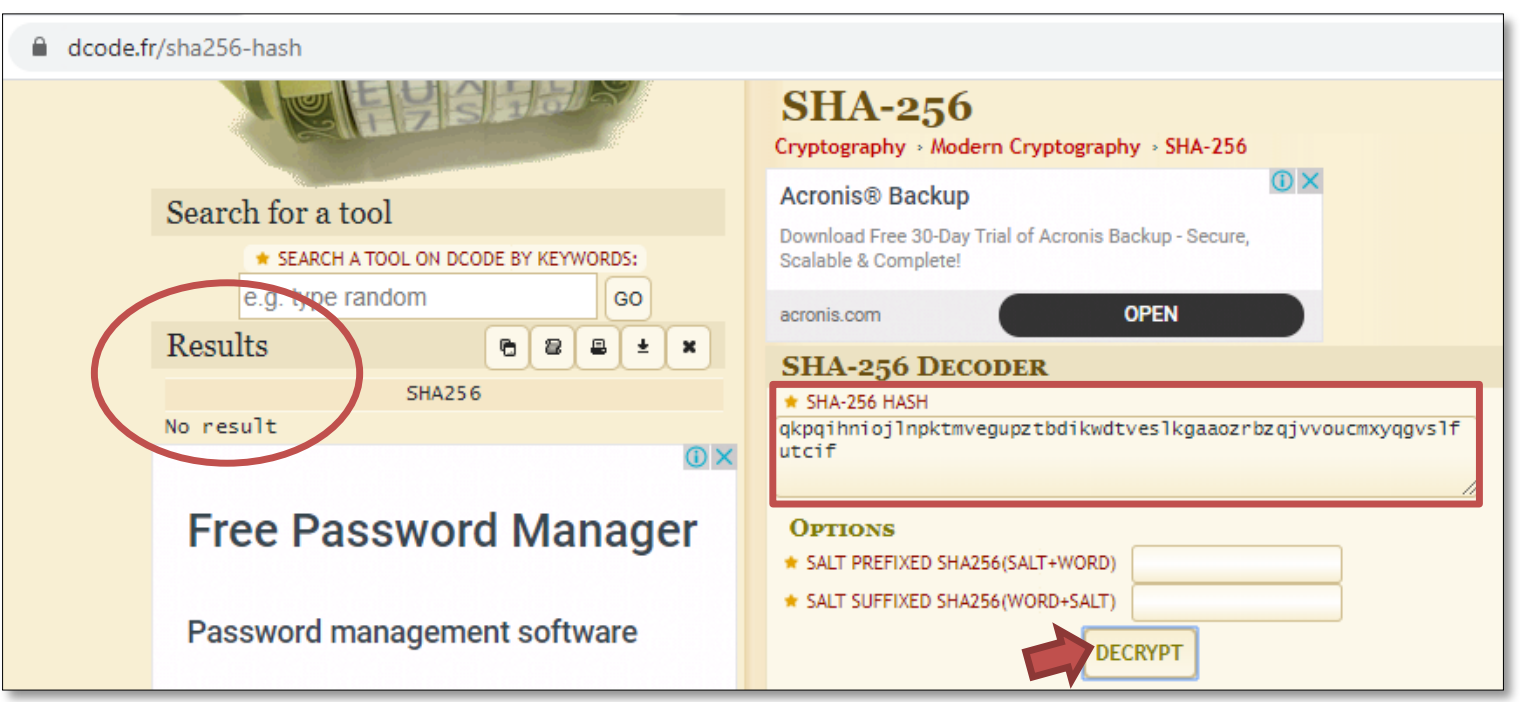

Gambar 7. Hasil Decode SHA-256 Modifikasi Hill Cipher

Program yang ada pada tools tersebut tidak dapat membaca pesan asli karena sudah dimodifikasi.

\section{KESIMPULAN}

Dari penelitian yang dilakukan dapat diambil kesimpulan :

1. Modifikasi SHA-256 dengan algoritma Hill Cipher dapat dilakukan untuk meningkatkan keamanan hash code agar tidak dapat didekripsi oleh tools decode hash yang beredar di internet.

2. algoritma Hill Cipher layak digunakan untuk memodifkasi sebuah hash code sebab tingkat keamanannya yang tergolong kuat. Hal ini dikarenakan kunci pada algoritma Hill Cipher tidak mudah untuk ditebak karena berbentuk matriks yang hanya pembuatnya yang mengetahui kunci tersebut.

3. Fungsi hash dewasa ini perlu untuk dijaga keamanannya agar tidak dapat di dekripsi oleh tools decode hash yang beredar di internet

\section{REFERENSI}

[1] R. K. Ibrahim, et al., "Incorporating Sha-2 256 With OFB To Relize A Novel Encryption Method" 2015 World Symposium on Computer Network and Information Security (WSCNIS) Hammamet, Tunisia, IEEE Transactions on Industrial Electronics”, Sep 2015, pp. 19-21.

[2] C. P. Sukhbir, et al., "Crypto Currencies for Digital Currency Using Cipher Text and SHA256" Jour of Adv Research in Dynamical \& Control Systems”, IEEE pp. 530-534, 2017

[3] S. S. Omran, et al., "Design Of SHA-1 \& SHA-2 MIPS Processor Using FPGA" Annual Conference on New Trends in Informations Technology Applications (NTICT 2017) : Hold at University of Information Technology and Communication", IEEE communication society, Iraq Chapeter, 7-9 Mar 2017, pp. 268-273.

[4] M. Eisenberg, "Hill Ciphers and Modular Linear Alebra," 1999 Mimegrophed Notes, University of Massachusetts, pp. 1-19. 
[5] D. Novriansyah, et al., "A New Image Encryption Technique Combining Hill Cipher Method, Morse Code and Least Significant Bit Algorithm”, Journal of Physics: Conference Series, 2018 vol 954.

[6] Z. E. Dewadeh, et al., "A New Image Encryption Technique Combining Elliptic Curve Cryptosystem with Hill Cipher," Journal of King Saud University-Computer and Information Sciences, pp.349-355

[7] J. I. Sari, et al., "Implementasi Penyembunyian Pesan pada Citra Digital dengan Menggabungkan Algoritma Hill Cipher dan Metode Least Significant Bit (LSB)", Jurnal Manajement dan Informatika Pelita Nusantara STMIK Pelita Nusantara Medan, 2015 vol:1.

[8] A. H. Hasugian, "Implementasi Algoritma Hill Cipher dalam Penyandian Data", ISSN 2301-9425. 